\title{
A valorização cultural do patrimônio geológico-mineiro do Paraná
}

\author{
Cultural enhancement of the earth and mining heritage of the state of Paraná \\ GILSON BURIGO GUIMARÃES ${ }^{1}$, ANTONIO LICCARDO ${ }^{1}$, GIL FRANCISCO PIEKARZ². \\ 1Universidade Estadual de Ponta Grossa-gburigo@ig.com.br - aliccardo@uepg.br \\ ${ }^{2}$ Minerais do Paraná S.A. - gil@mineropar.pr.gov.br
}

\begin{abstract}
Resumo
O estado do Paraná apresenta características geológicas peculiares em função de sua clara compartimentação espaço-temporal, tendo recebido um aporte de pesquisas desde o século XIX com escopo essencialmente prospectivo para a mineração e desenvolvimento geocientífico. Com base no conhecimento acumulado e com um novo paradigma científico que aponta a valorização de aspectos não necessariamente extrativistas da geologia, este trabalho propõe uma discussão preliminar sobre os pontos que constituem o patrimônio geológico e mineiro do estado e seu aproveitamento para fins diferentes da mineração. São apresentados os resultados de iniciativas ligadas ao patrimônio geológico no Paraná, tais como o Programa SIGEP (nacional) e da Mineropar, além de uma relação preliminar dos geossítios e áreas representativas do patrimônio geológico do estado. A sensibilização da comunidade científica para algumas questões de geoconservação aponta para dois pontos-chave: a necessidade do maior envolvimento científico dos geólogos na valorização do patrimônio e a transposição didática do conhecimento geológico para leigos. Estes desafios constituem um novo paradigma em que tão importante quanto desenvolver o conhecimento geocientífico é comunicá-lo à sociedade, de modo a aumentar a massa crítica e permitir melhores tomadas de decisão no planejamento por parte do poder público e da iniciativa privada.
\end{abstract}

Palavras-chave: patrimônio geológico; patrimônio mineiro; geodiversidade; estado do Paraná

\begin{abstract}
The state of Paraná shows a peculiar set of geological features, closely related to its spatial and temporal framework, which has been researched since the nineteenth century, mainly for mining and geoscientific purposes. Based on the accumulated knowledge and a new scientific paradigm, that points to valuing aspects not necessarily linked to economic geology, this paper proposes a preliminary discussion of the geosites that make up the earth and mining heritage of the state and its use other than to mineral exploration and mining activities. Earth heritage initiatives are presented, such as the SIGEP Program (Brazilian Commission of Geological and Palaeobiological Sites) and from Mineropar (State of Paraná Geological Survey), with a preliminary list of the geosites and representative areas of the earth heritage of the state of Paraná. The awareness of the scientific community for geoconservation issues leads to two key points: the need for greater scientific involvement of geologists in the valuation process of the heritage, and the didactic transposition of geological knowledge to lay person. These challenges constitute a new paradigm, where as important as developing the geoscientific knowledge is bring it to the society, increasing the critical mass and enabling wise decisions at the planning-level by the government and the private sector.
\end{abstract}

Key words: earth heritage; mining heritage; geodiversity; state of Paraná.

\section{INTRODUÇÃO}

As rochas e os minerais, assim como outros objetos do estudo geológico (geomorfologia, solos...), representam importante fonte de informações tradicionalmente ligada à potencialidade de uso que podem apresentar. A prospecção mineral ou a capacidade agrícola dos terrenos impulsionaram a evolução da sociedade e trouxeram um valioso aprendizado sobre várias facetas da geodiversidade. Entretanto, preocupações ligadas ao meio ambiente, assim como os processos de valorização da memória coletiva, conduziram ao surgimento de novos conceitos sobre patrimônio, que vão além dos aspectos puramente econômicos.

Não obstante a geodiversidade brasileira ser normalmente tratada como mercadoria, ou seja, materiais que possam ser produzidos e quantificados em unidades monetárias por tonelada, existem outros aspectos que passaram a ser valorizados nos últimos anos e que indicam uma mudança conceitual no uso da informação geológica. As geociências apresentaram profundo progresso nas últimas décadas, amparado não somente pela tecnologia, mas também por um amadurecimento científico e cultural traduzido em responsabilidade e consciência ambiental. Todo o conhecimento gerado inicialmente para a busca de minérios hoje se reflete também em outras interfaces com a sociedade, como estudos de áreas de risco, 
de poluição, geoturismo ou mesmo questões culturais. 0 próprio resultado da atividade de mineração é um conjunto cultural valioso para o entendimento da evolução social, denominado hoje como patrimônio mineiro, e que apresenta forte correlação com a Arqueologia Industrial.

Desde 1972, a UNESCO promove a evolução do significado de patrimônio, inicialmente dividido em natural e cultural, mas que depois recebeu um maior aporte intelectual para a definição de patrimônio imaterial. Mais recentemente discute-se internacionalmente o conceito de patrimônio geológico (ver Gray, 2004; Brilha, 2005; dentre outros), discussão esta que não pode prescindir do conhecimento acumulado por geólogos, mas que também não deve ser exclusividade destes profissionais.

O Paraná é um dos estados brasileiros que apresenta uma história de aprimoramento do conhecimento geológico que remonta aos tempos do Brasil colonial, com relatórios técnicos tais como os de José Bonifácio e Martim Francisco (Andrada, 1847), movidos pela exploração mineral de ouro e diamante, ou os trabalhos de White (republicados em 2008) pelos recursos energéticos (carvão). O capital científicocultural acumulado com todos os levantamentos já realizados neste território, seja pelos próprios autores ou disponível em outros trabalhos, permite hoje a possibilidade de discussão a respeito de um patrimônio geológico do estado, tema que este artigo se propõe a apresentar à comunidade geológica, considerando especialmente sua geodiversidade como fator cultural e voltado à possível educação científica em vários níveis, além do potencial econômico.

Alicerçado em um volume de pesquisas da ordem de milhares de monografias, mapas, artigos, livros, teses, relatórios técnicos, desde os estudos pioneiros do século XIX, pode-se afirmar com segurança que o Paraná é um estado com uma expressiva geodiversidade, no sentido defendido por Gray (2004). Do Paleoproterozoico (eventualmente desde o Arqueano) ao Holoceno encontra-se um amplo espectro de produtos magmáticos, sedimentares e metamórficos, em diferentes ambientes geotectônicos, controlando uma variada gama de tipos de solos, formas de relevo e mineralizações. Uma parte deste conteúdo constitui o que vem sendo denominado Patrimônio Geológico. O histórico de utilização extrativista conduz à possibilidade de se considerar a mineração em certos pontos como parte de um Patrimônio Mineiro (Liccardo \& Cava, 2006).

\section{PATRIMÔNIO GEOLÓGICO E MINEIRO}

O conjunto dos geossítios de um lugar que apresentem valor singular do ponto de vista científico, didático, cultural, turístico, econômico ou funcional, compõe seu o Patrimônio Geológico, conforme Brilha (2005). Ponciano et al. (2011) propõem, ainda, uma subclassificação em patrimônio geológico in situ (o acima citado) e ex situ (como as coleções científicas, museus aquele que foi retirado de seu lugar de origem). Dado o caráter preliminar dos levantamentos, este trabalho discute apenas o primeiro caso, não obstante a importância do segundo para a educação.

Nos últimos anos diversos autores têm contribuído para um entendimento geral deste conceito e para sua aplicação específica à geodiversidade (Sharples, 2002; Gray, 2004; Brilha, 2005; Carcavilla et al., 2007; Nascimento et al., 2008; Mochiutti, 2013), com uma forte tendência em se selecionar geossítios de destacada importância científica para compor o Patrimônio Geológico de uma dada região. Porém, ao considerar que um dos desafios atuais da comunidade geocientífica é o de alcançar a sociedade em geral, a apresentação das áreas de destaque da geodiversidade do estado não pode enfatizar apenas aquelas de valor científico-acadêmico. O ponto-chave é que há várias frentes de atuação, das quais a educação (formal, não formal e informal) em todos os níveis deve ser privilegiada.

É preciso considerar um patrimônio geológico que seja reconhecido por parte expressiva da sociedade e que não tenha apenas um caráter "corporativo". É igualmente importante aos locais com valor científico que apresentem também outros valores da geodiversidade, como os culturais, didáticos ou estéticos, por exemplo. Zelar pela integridade de locais que somente uma minoria (geólogos) consegue percebêlos como especiais é tão relevante quanto ampliar a parcela da população em condições de entender e apreciar a geologia e seus segredos. Ambas as linhas de intervenção necessitam da participação direta dos profissionais de geociências, o que implica num compromisso de aumentar seus esforços para traduzir à comunidade o significado de rochas, minerais, fósseis, formas de relevo, solos e os processos que os geram.

Um inventário do Patrimônio Geológico do Paraná embasado em procedimentos metodológicos cientificamente debatidos (Brilha, 2005; Lima, 2008), ainda está por ser realizado. 0 estabelecimento de uma hierarquia e classes deverá levar em conta as múltiplas variantes da geologia (estratigrafia; petrologia; geologia estrutural / geotectônica; mineração; mineralogia; geomorfologia; paleontologia; geologia ambiental; sedimentologia, etc.) e os grandes domínios tectônicotemporais responsáveis pela geodiversidade paranaense (rochas e estruturas pré-brasilianas e brasilianas; sequências sedimentares da Bacia do Paraná; produtos magmáticos, sedimentares e estruturais ligados ao processo de abertura do Oceano Atlântico; etc.).

Uma vez que se pretenda ampliar o alcance do conceito de patrimônio geológico, este inventário deverá também contemplar elementos da geodiversidade com valores culturais, estéticos, didáticos e funcionais (Gray, 2004), em consonância com o entendimento de 
patrimônio apregoado pela UNESCO.

A história da mineração tem sido usada em muitos países como um fator de resgate cultural para comunidades que se desenvolveram em áreas de extração intensa. Na Europa verificam-se vestígios de mineração dos tempos do Império Romano ou anteriores, os quais têm sido preservados e resgatados como um aspecto da memória e patrimônio cultural dos lugares trabalhados. O conteúdo material relacionado (ruínas, pedreiras, equipamentos...), assim como os aspectos intangíveis (cultura, memória, miscigenação...) são hoje considerados Patrimônio Mineiro, vertente da discussão em torno do Patrimônio Geológico. Num país como o Brasil, de histórico fortemente ligado à mineração, estes patrimônios podem convergir facilmente.

\section{INICIATIVAS DE VALORIZAÇÃO DO PATRIMÔNIO GEOLÓGICO E MINEIRO DO PARANÁ}

Curitiba, capital precursora no Brasil em vários aspectos urbanísticos, foi pioneira na valorização do Patrimônio Mineiro, mesmo que não tenha sido esta a intenção inicial, no começo da década de 1990. Num planejamento ousado, que rendeu grande visibilidade ao município, várias frentes de lavra desativadas foram transformadas em parques e áreas de lazer público, o que hoje fornece ao turismo a maior parte de seu atrativo na cidade. Não obstante as informações geológicas terem sido esquecidas, por exemplo, na divulgação do Parque Tanguá, Pedreira Paulo Leminski, Universidade Livre do Meio Ambiente e Zoológico Municipal, estes pontos considerados entre os principais atrativos turísticos colocam o visitante em contato com um resgate da história de mineração de Curitiba. Liccardo et al. (2008) apresentaram esta correlação entre a geologia e história da mineração nos parques com os aspectos culturais atualmente divulgados, buscando uma associação com o uso turístico (geoturismo). Em vários casos ainda é possível encontrar importantes vestígios da atividade, como britadores e outros equipamentos no Parque Tanguá.

Somente a partir de 2003 o Patrimônio Geológico passou a ser discutido no Paraná e isto aconteceu dentro de três grandes movimentos em prol de sua valorização e conservação. O primeiro coube à Mineropar, o Serviço Geológico do Paraná, através do projeto Sítios Geológicos e Paleontológicos do Paraná tendo como um de seus principais resultados a implantação de 48 painéis, presentes em 20 pontos de leste a oeste do Paraná (Figura 1). No âmbito deste projeto ainda foram editados dois livros (Geoturismo em Curitiba e Geoturismo no Karst) com a seleção de geossítios do município de Curitiba e mais três municípios vizinhos à capital paranaense, estando um terceiro programado para 2013 (Geoturismo em Tibagi).

Outro movimento ligado a esta temática aconteceu com a participação na lista brasileira de sítios geológicos e paleobiológicos, a SIGEP. Nela o Paraná está representado com 13 áreas, entre geossítios publicados e propostas (Figura 1). Há uma evidente distribuição desigual ao longo do território, pois nove dos geossítios se situam no contexto dos Campos Gerais do Paraná, borda leste do Segundo Planalto Paranaense. No projeto da Mineropar, mesmo com uma distribuição mais ampla que os geossítios da SIGEP, também existe uma concentração de intervenções na área dos Campos Gerais. Assim, não é surpresa o fato de inúmeras instituições de ensino, do nível fundamental ao superior, do próprio estado ou não, elegerem esta região como um de seus destinos preferenciais para trabalhos de campo e visitas técnicas de diversas disciplinas das geociências (Guimarães et al., 2006; Melo et al., 2007; Guimarães et al., 2009; Melo e Guimarães, 2012).

Estas duas iniciativas valorizam e divulgam aspectos da geodiversidade estadual, inclusive com sobreposição de temas, sendo concebidas para públicos diferentes (especializado para o SIGEP e mais genérico nos painéis da Mineropar). A divulgação e o alcance resultantes também foram distintos, seja por publicação de livros e pela internet (SIGEP) ou diretamente pela visita aos geossítios (painéis). O conjunto, entretanto, está longe de constituir um panorama pleno do patrimônio geológico existente no Paraná.

A terceira estratégia, menor em quantidade de geossítios, porém de extrema importância para a geoconservação, foi uma consequência dos movimentos anteriores. Foi o processo de tombamento de quatro geossítios (Estrias de Witmarsum, Icnofósseis de São Luiz do Purunã, Cratera de Impacto em Coronel Vivida e Sítio Fossilífero de Pterossauros em Cruzeiro do Oeste) junto à Secretaria da Cultura do Paraná, tornando-os parte integrante do patrimônio natural do Paraná de acordo com seu valor cultural. $\mathrm{O}$ tombamento destes geossítios não obedeceu a uma estratégia pré-concebida, o que seria mais adequado, mas sim a necessidades imediatas de preservação de sítios que se encontravam sob o risco iminente de perda de sua integridade. No Paraná a política de tombamento pode se configurar numa importante ferramenta legal para a preservação e conservação do patrimônio geológico (Piekarz et al, 2012).

\section{LISTA PRELIMINAR DO PATRIMÔNIO GEOLÓGICO PARANAENSE}

Mesmo com a carência atual de levantamentos que ponderem a relevância científica de geossítios no estado do Paraná, as ações anteriores fornecem subsídios para a proposição de um conjunto preliminar representativo de seu Patrimônio Geológico-Mineiro (Tabela 1), o qual traduz os principais acontecimentos da história da Terra presentes no território paranaense (figuras 2 a 15) e que ajudaram a construir a 
Plataforma Sul-Americana, com destaque para produtos do Ciclo Brasiliano, supersequências paleozoicas e mesozoicas da principal sinéclise desta plataforma (Bacia do Paraná), fenômenos associados à abertura do Oceano Atlântico-Sul e à deriva da Placa Sul-Americana, além do modelado cenozoico do relevo.

São incluídos locais com diferentes níveis de atratividade e acessibilidade, mas que permitem interpretar geoprocessos que não sejam demasiadamente complexos com relativa facilidade de transposição didática. Alguns deles já apresentam estruturas diretamente ligadas ao geoturismo, e que têm servido também como ferramenta de educação não formal e combinam valores científicos, didáticos, culturais, estéticos e funcionais

Para uma primeira aproximação da geodiversidade do Paraná (por exemplo, para alunos de ensino médio e fundamental e geoturistas), o conjunto de geossítios A a $\mathrm{G}$ (Tabela 1) permite reconhecer as grandes unidades de relevo e a maior parte dos principais episódios da história geológica do estado. Estes se situam em unidades de conservação públicas, ou seja, parques municipais (geossítio C) e estaduais (geossítios $A, B, E$ ), um parque nacional (geossítio $\mathrm{G}$ ) e áreas de proteção ambiental (geossítios D, F), o que facilita o reconhecimento de conexões com a biodiversidade (valor funcional), viabilizando uma percepção integral de aspectos diversos do patrimônio natural estadual.
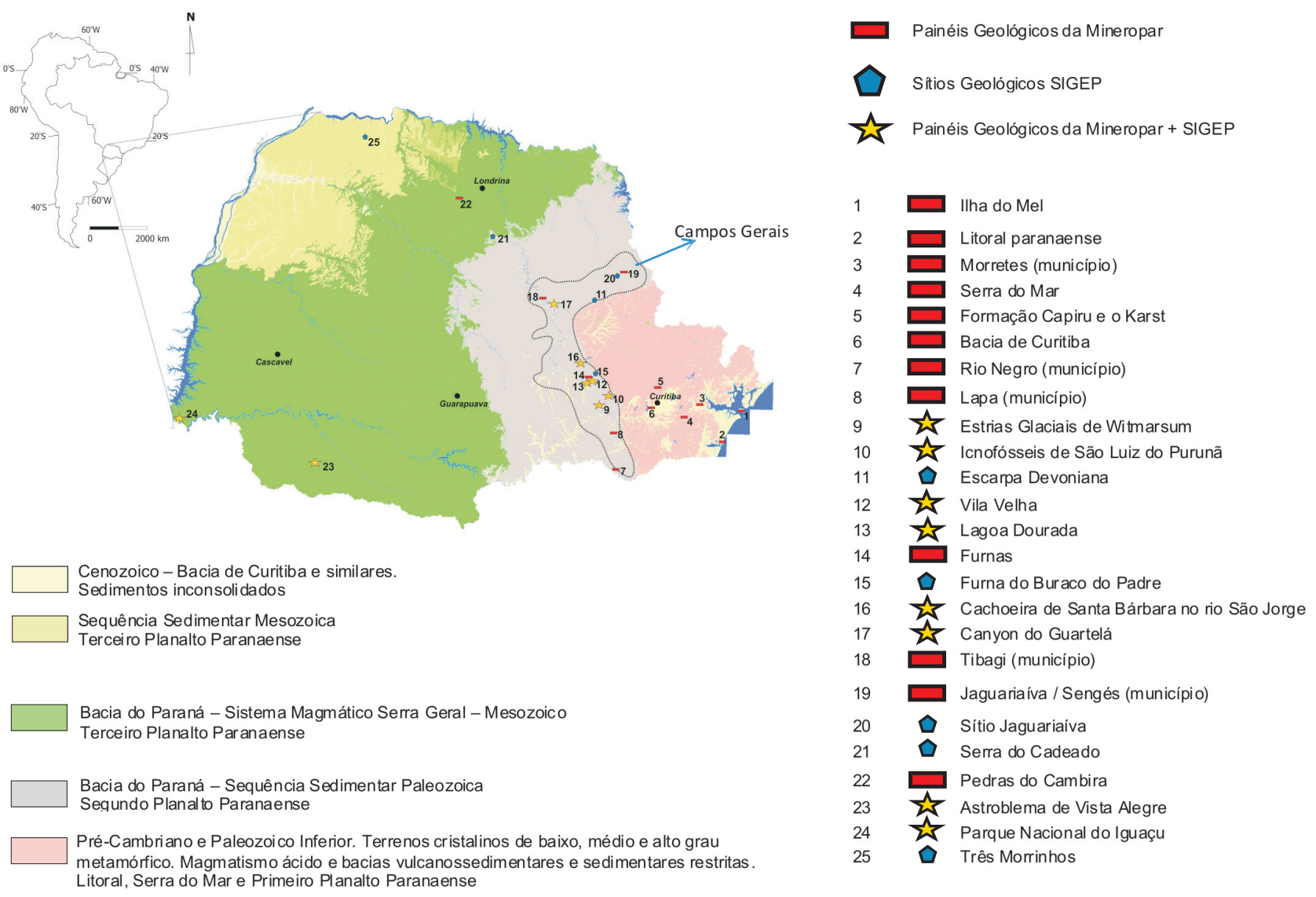

Figura 1 - Mapa geológico simplificado do Estado do Paraná com indicação dos geossítios cadastrados no SIGEP e dos painéis instalados pela Mineropar. Fonte: Mineropar. 
Tabela 1-Lista preliminar de geossítios representativos do patrimônio geológico do Paraná.

\begin{tabular}{|c|c|c|c|}
\hline Geosítio & Nome & Localização & Contexto Geológico \\
\hline A & Ilha do Mel & Litoral & $\begin{array}{l}\text { Rochas do Ciclo Brasiliano, Magmatismo Serra Geral, } \\
\text { abertura do Oceano Atlântico, transgressões-regressões } \\
\text { quaternárias, dinâmica litorânea }\end{array}$ \\
\hline B & Complexo Marumbi & Serra do Mar & $\begin{array}{l}\text { Magmatismo granítico brasiliano, Sistema de Riftes } \\
\text { Cenozoicos do Sudeste do Brasil, evolução do relevo, } \\
\text { movimentos de massa eáreas de risco }\end{array}$ \\
\hline C & $\begin{array}{l}\text { Grutas de Bacaetava e } \\
\text { Lagoa Verde }\end{array}$ & $\begin{array}{l}\text { Primeiro Planalto } \\
\text { Paranaense }\end{array}$ & $\begin{array}{l}\text { Sedimentação carbonática da Formação Capiru, faixa de } \\
\text { dobramentos brasiliana, recursos minerais (rochas } \\
\text { carbonáticas), relevo e aquífero cárstico, riscos } \\
\text { geológicos }\end{array}$ \\
\hline D & $\begin{array}{l}\text { Mirante do Cristo/São } \\
\text { Luiz do Purunã }\end{array}$ & Escarpa Devoniana & $\begin{array}{l}\text { Contato Bacia do Paraná-Embasamento, faixa de } \\
\text { dobramentos brasiliana (Formação Votuverava), } \\
\text { Sequência Paraná da Bacia do Paraná, contraste } \\
\text { geológico-geomorfológico do 10 e } 2 \text { o planaltos }\end{array}$ \\
\hline$E$ & $\begin{array}{l}\text { Parque Estadual de Vila } \\
\text { Velha }\end{array}$ & $\begin{array}{l}\text { Segundo Planalto } \\
\text { Paranaense }\end{array}$ & $\begin{array}{l}\text { Sequências Paraná e Gondwana I (base), relevo } \\
\text { ruiniforme, carste em arenitos }\end{array}$ \\
\hline $\mathrm{F}$ & $\begin{array}{l}\text { Mirante do } \\
\text { Morungava/Serra da } \\
\text { Esperança }\end{array}$ & Escarpa da Serra Geral & $\begin{array}{l}\text { Topo da Sequência Gondwana I (formações Rio do Rasto } \\
\text { e Piramboia), Gondwana III, contraste geológico- } \\
\text { geomorfológico do } 2 \text { o e } 3 \text { o planaltos, área de recarga do } \\
\text { Aquífero Guarani }\end{array}$ \\
\hline G & $\begin{array}{l}\text { Parque Nacional do } \\
\text { Iguaçu }\end{array}$ & $\begin{array}{l}\text { Terceiro Planalto } \\
\text { Paranaense }\end{array}$ & $\begin{array}{l}\text { Magmatismo Serra Geral, Cataratas do Iguaçu } \\
\text { (Patrimônio da Humanidade), principal rio } \\
\text { eminentemente paranaense(riolguaçu) }\end{array}$ \\
\hline $\mathrm{H}$ & Pico Paraná & Serra do Mar & $\begin{array}{l}\text { Magmatismo granítico brasiliano, Sistema de Riftes } \\
\text { Cenozoicos do Sudeste do Brasil, evolução do relevo, } \\
\text { movimentos de massa e áreas de risco, ponto } \\
\text { culminante do Paraná e da região sul do país }\end{array}$ \\
\hline I & $\begin{array}{l}\text { Parque Municipal Aníbal } \\
\text { Khury }\end{array}$ & $\begin{array}{l}\text { Primeiro Planalto } \\
\text { Paranaense }\end{array}$ & $\begin{array}{l}\text { Faixa de dobramentos brasiliana, sedimentação } \\
\text { carbonática da Formação Capiru }\end{array}$ \\
\hline $\mathrm{J}$ & $\begin{array}{l}\text { Formação Guabirotuba } \\
\text { (Cidade Industrial de } \\
\text { Curitiba) }\end{array}$ & $\begin{array}{l}\text { Primeiro Planalto } \\
\text { Paranaense }\end{array}$ & $\begin{array}{l}\text { Sedimentação plio / pleistocênica da Bacia de Curitiba, } \\
\text { mudanças climáticas globais, fósseis de vertebrados, } \\
\text { contato com embasamento }\end{array}$ \\
\hline K & $\begin{array}{l}\text { Parques-pedreiras de } \\
\text { Curitiba }\end{array}$ & $\begin{array}{l}\text { Primeiro Planalto } \\
\text { Paranaense }\end{array}$ & $\begin{array}{l}\text { Rochas meso a paleoproterozoicas retrabalhadas no } \\
\text { Ciclo Brasiliano }\end{array}$ \\
\hline $\mathrm{L}$ & $\begin{array}{l}\text { Mina da Plumbum em } \\
\text { Adrianópolis }\end{array}$ & $\begin{array}{l}\text { Primeiro Planalto } \\
\text { Paranaense }\end{array}$ & $\begin{array}{l}\text { Mineração de chumbo e zinco, faixa de dobramentos } \\
\text { brasiliana, sedimentação carbonática }\end{array}$ \\
\hline M & Estrias de Witmarsum & $\begin{array}{l}\text { Segundo Planalto } \\
\text { Paranaense }\end{array}$ & $\begin{array}{l}\text { Sequências Paraná e Gondwana I, Glaciação } \\
\text { Permocarbonífera, deriva continental, mudanças } \\
\text { climáticasglobais }\end{array}$ \\
\hline $\mathrm{N}$ & $\begin{array}{l}\text { Monumento da Pedra } \\
\text { Caída em Rio Negro }\end{array}$ & $\begin{array}{l}\text { Segundo Planalto } \\
\text { Paranaense }\end{array}$ & $\begin{array}{l}\text { Sequência Gondwana I, Glaciação Permocarbonífera, } \\
\text { fósseis }\end{array}$ \\
\hline $\mathrm{O}$ & $\begin{array}{l}\text { Parque Nacional dos } \\
\text { Campos Gerais }\end{array}$ & $\begin{array}{l}\text { Segundo Planalto } \\
\text { Paranaense }\end{array}$ & $\begin{array}{l}\text { Em diversos geossítios (Buraco do Padre, Furnas } \\
\text { Gêmeas, Cachoeira de Santa Bárbara, etc.): } \\
\text { magmatismo granítico brasiliano, sequências Rio Ivaí e } \\
\text { Paraná, estruturas do Arco de Ponta Grossa, contraste } \\
\text { geológico-geomorfológico do 1o e 2o planaltos, carste } \\
\text { emarenitos, Aquífero Furnas }\end{array}$ \\
\hline
\end{tabular}




\begin{tabular}{|c|c|c|c|}
\hline$P$ & $\begin{array}{l}\text { Parque Estadual do } \\
\text { Guartelá }\end{array}$ & $\begin{array}{l}\text { Segundo Planalto } \\
\text { Paranaense }\end{array}$ & $\begin{array}{l}\text { Bacias molássicas tardibrasilianas (Grupo Castro), } \\
\text { sequências Rio Ivaí e Paraná, diques do Magmatismo } \\
\text { Serra Geral, estruturas do Arco de Ponta Grossa, } \\
\text { contraste geológico-geomorfológico do 1o e 2o } \\
\text { planaltos, drenagens antecedentes (canyon do rio } \\
\text { lapó), carste emarenitos }\end{array}$ \\
\hline Q & Diamante do Rio Tibagi & $\begin{array}{l}\text { Segundo Planalto } \\
\text { Paranaense }\end{array}$ & $\begin{array}{l}\text { Sequências Paraná e Gondwana I (base), diques do } \\
\text { Magmatismo Serra Geral, recursos minerais (diamante e } \\
\text { ouro), geomorfologia fluvial }\end{array}$ \\
\hline $\mathrm{R}$ & Carvão de Figueira & $\begin{array}{l}\text { Segundo Planalto } \\
\text { Paranaense }\end{array}$ & $\begin{array}{l}\text { Sequência Gondwana I (Formação Rio Bonito), Flora } \\
\text { Glossopteris, deriva continental, recursos minerais } \\
\text { (carvão, urânio eágua) }\end{array}$ \\
\hline $\mathrm{S}$ & $\begin{array}{l}\text { Folhelho betuminoso de } \\
\text { São Mateus do Sul }\end{array}$ & $\begin{array}{l}\text { Segundo Planalto } \\
\text { Paranaense }\end{array}$ & $\begin{array}{l}\text { Sequência Gondwana I (Formação Irati), fósseis, deriva } \\
\text { continental, recursos minerais (óleo, gás, enxofre, argila) }\end{array}$ \\
\hline $\mathrm{T}$ & $\begin{array}{l}\text { Cachoeiras de } \\
\text { Prudentópolis }\end{array}$ & $\begin{array}{l}\text { Segundo e Terceiro } \\
\text { Planaltos Paranaenses }\end{array}$ & $\begin{array}{l}\text { Em diversos geossítios (saltos São Francisco, São João, } \\
\text { Barão do Rio Branco, etc.): topo da Sequência } \\
\text { Gondwana I (formações Teresina, Rio do Rasto e } \\
\text { Piramboia), Gondwana III, soleiras do Magmatismo } \\
\text { Serra Geral, contraste geológico-geomorfológico do 2o } \\
\text { e 3o planaltos, maior cachoeira do sul do Brasil (Salto } \\
\text { São Francisco), área de recarga do Aquífero Guarani }\end{array}$ \\
\hline$U$ & $\begin{array}{l}\text { Astroblema de Vista } \\
\text { Alegre }\end{array}$ & $\begin{array}{l}\text { Terceiro Planalto } \\
\text { Paranaense }\end{array}$ & $\begin{array}{l}\text { Sequência Gondwana III, feições de impacto } \\
\text { meteorítico, formas especiais de relevo, eventos } \\
\text { singularese seus efeitos }\end{array}$ \\
\hline $\mathrm{V}$ & $\begin{array}{l}\text { Mina de Ametista em } \\
\text { Chopinzinho }\end{array}$ & $\begin{array}{l}\text { Terceiro Planalto } \\
\text { Paranaense }\end{array}$ & $\begin{array}{l}\text { Magmatismo Serra Geral e mineralização de quartzo } \\
\text { violeta em geodos }\end{array}$ \\
\hline
\end{tabular}

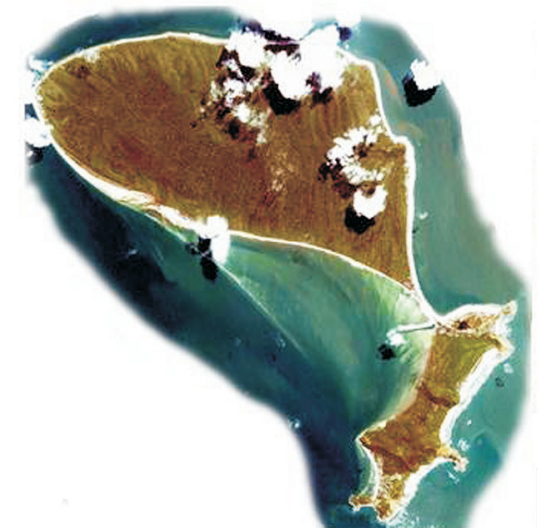

Figura 2 - Ilha do Mel, geossítio representativo do patrimônio geológico do Litoral (acervo Mineropar).

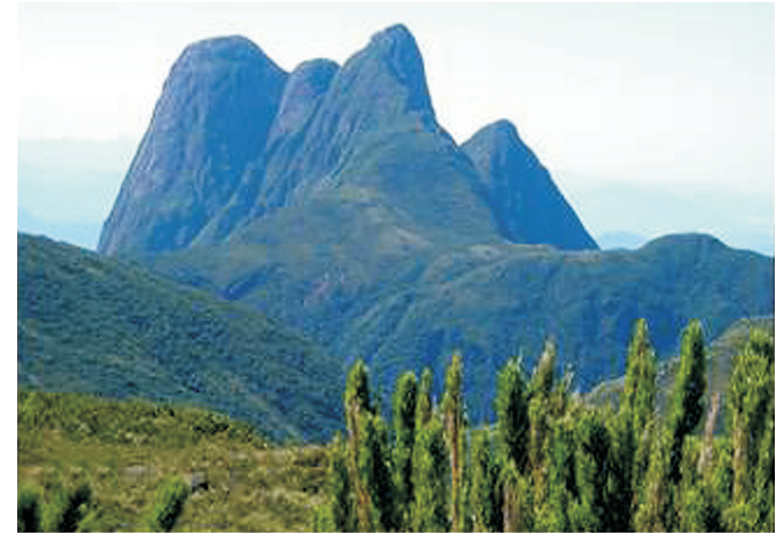

Figura 3 - Pico do Paraná, geossítio representativo do patrimônio geológico na transição Litoral/Primeiro Planalto Paranaense (Serra do Mar). 


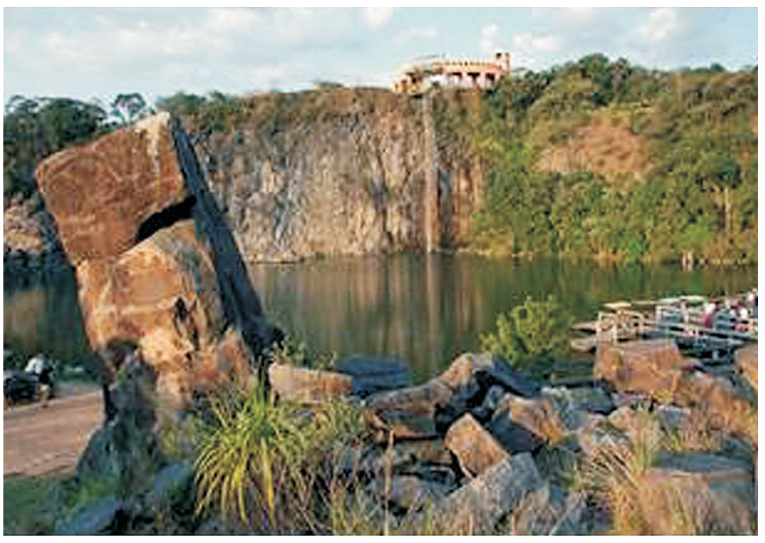

Figura 4-Parque Tanguá (Curitiba), geossítio representativo do patrimônio geológico-mineiro do Primeiro Planalto Paranaense.

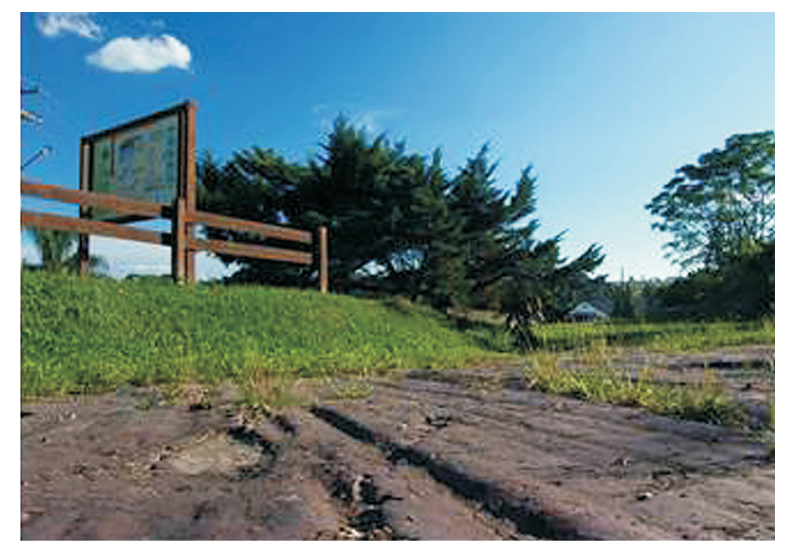

Figura 6 - Estrias Glaciais de Witmarsum (Palmeira), geossítio representativo do patrimônio geológico do Segundo Planalto Paranaense.

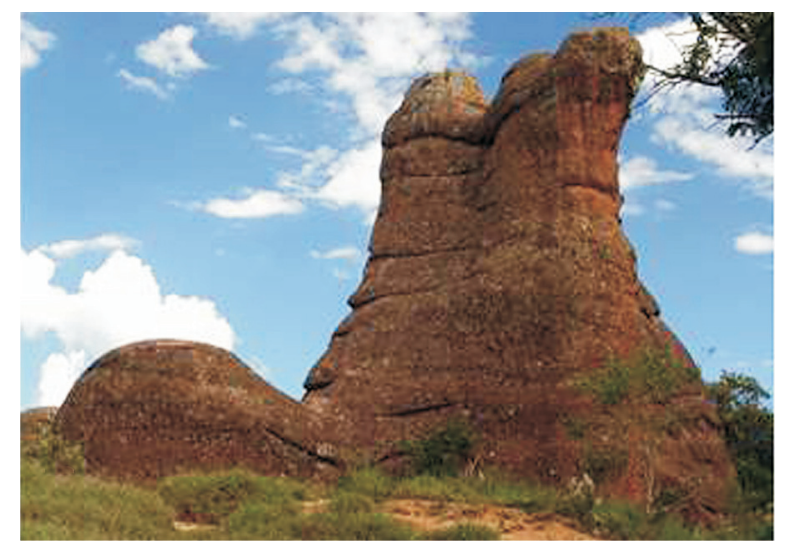

Figura 8 - Parque Estadual de Vila Velha (Ponta Grossa), geossítio representativo do patrimônio geológico do Segundo Planalto Paranaense.

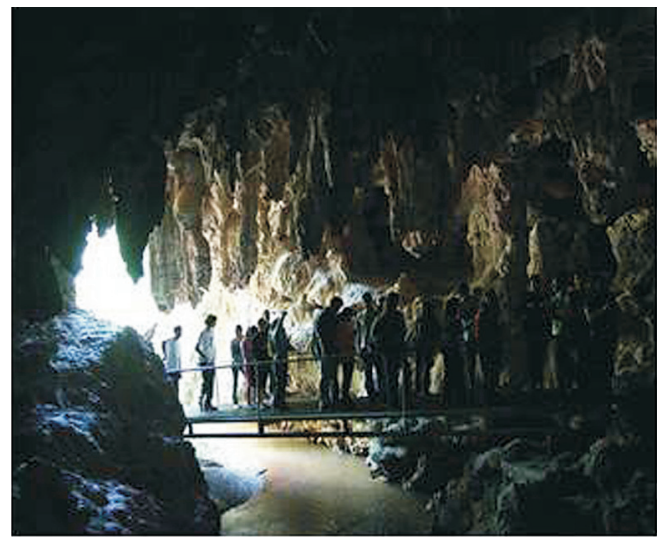

Figura 5 - Gruta Bacaetava (Colombo), geossítio representativo do patrimônio geológico do Primeiro Planalto Paranaense.

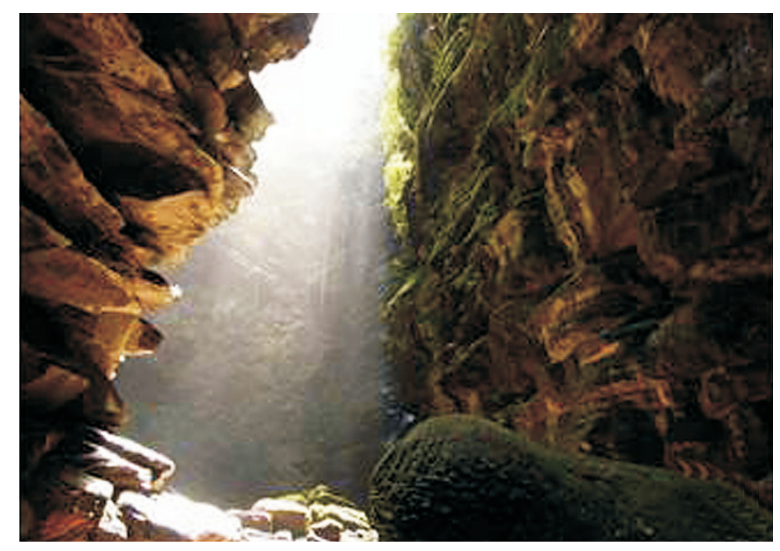

Figura 7 - Buraco do Padre (Ponta Grossa), geossítio representativo do patrimônio geológico do Segundo Planalto Paranaense.

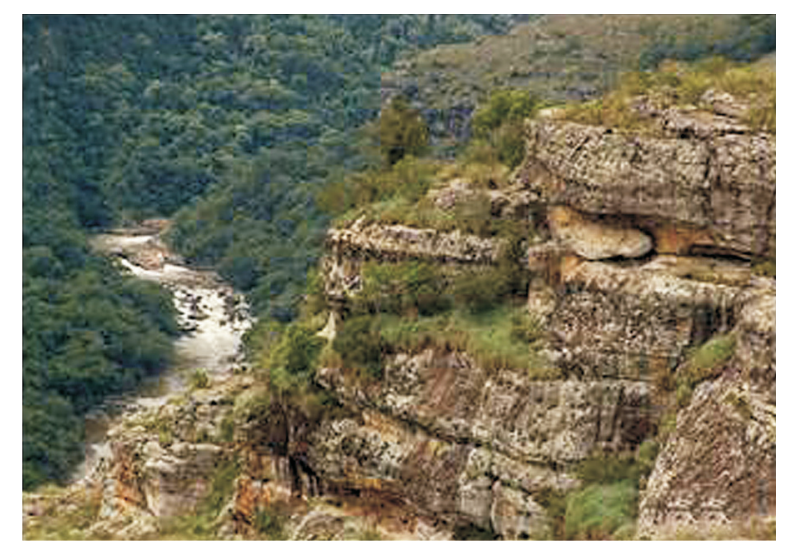

Figura 9 - Canyon do Guartelá (Castro/Tibagi), geossítio representativo do patrimônio geológico do Segundo Planalto Paranaense. 


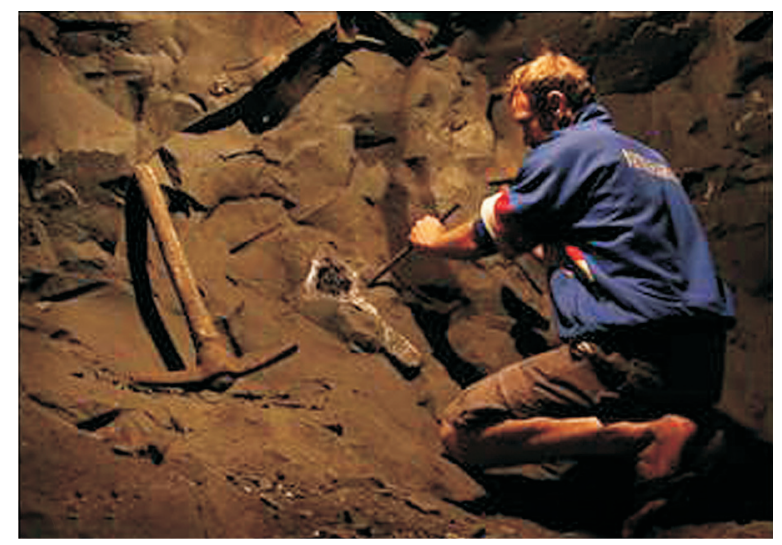

Figura 10 - Extração de geodos de ametista no basalto (Chopinzinho), geossítio representativo do patrimônio geológico-mineiro do Terceiro Planalto Paranaense.

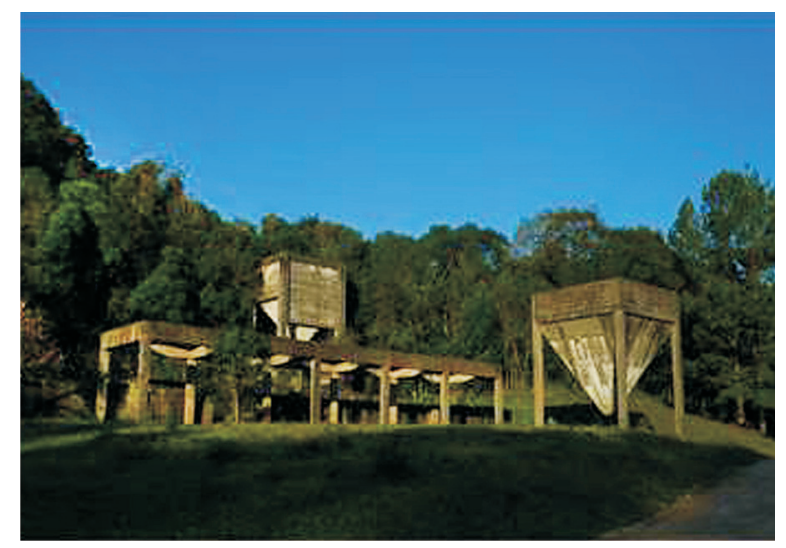

Figura 12 - Vestígios da mineração de ouro em Timbotuva (Campo Largo), imagem representativa da história da mineração no Paraná.

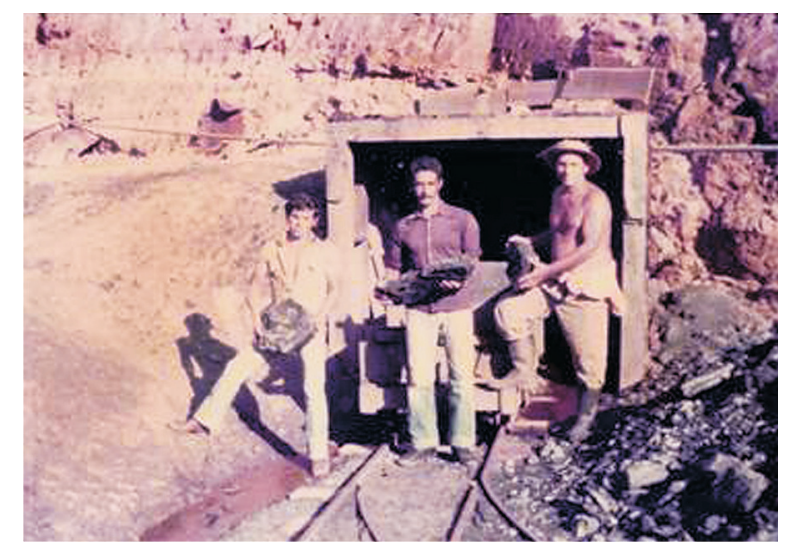

Figura 14 - Mina de carvão em Ortigueira, ativa até a década de 1970.

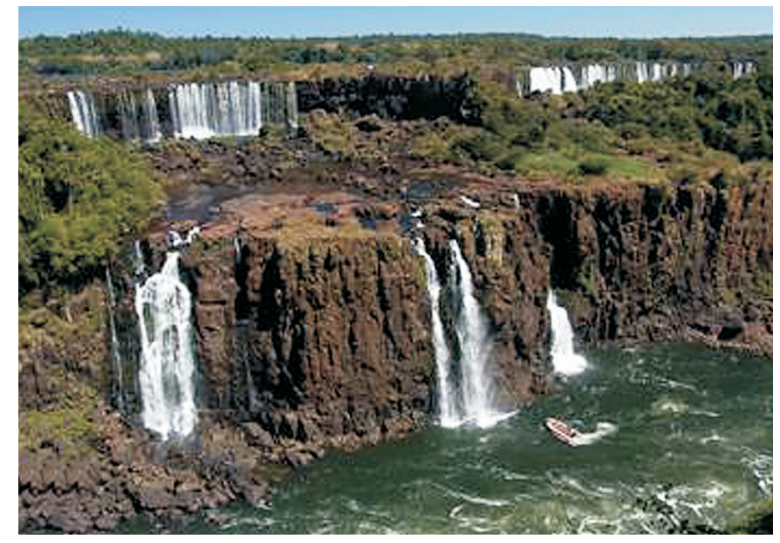

Figura 11 - Parque Nacional do Iguaçu (Foz do Iguaçu), geossítio representativo do patrimônio geológico do Terceiro Planalto Paranaense.

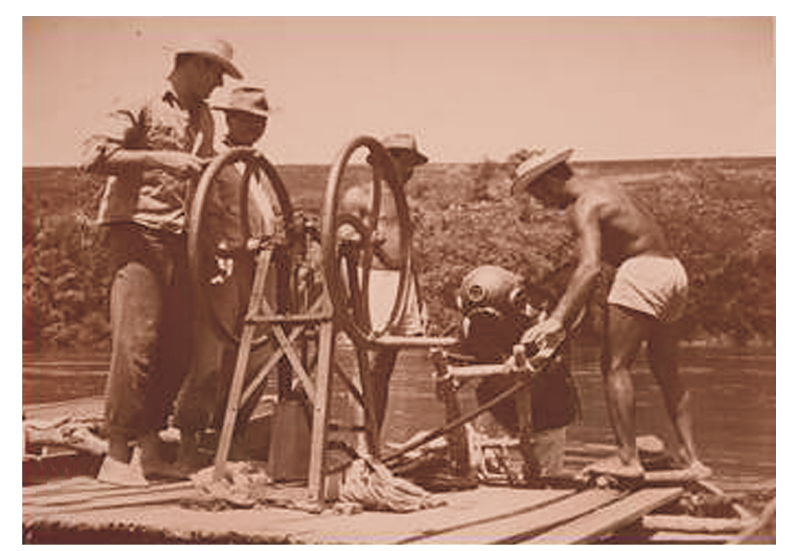

Figura 13 - Extração de diamantes por mergulho com escafandros (Tibagi/1935).

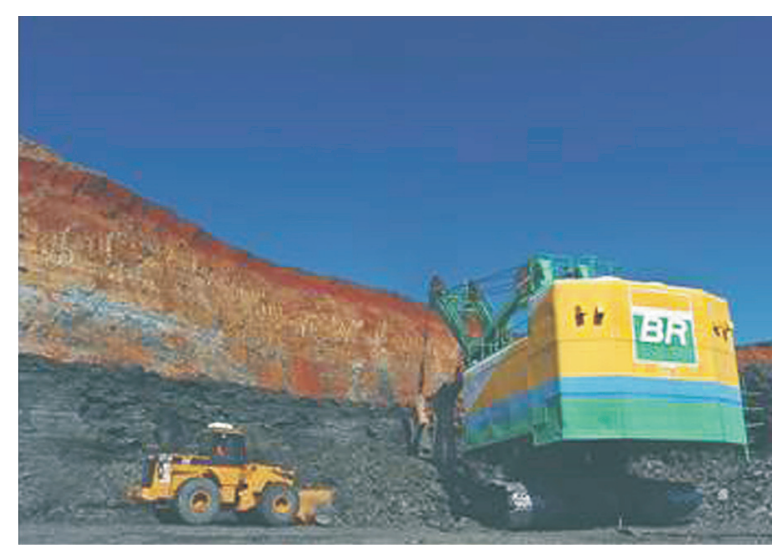

Figura 15 - Extração de folhelho pirobetuminoso (São Mateus do Sul). 


\section{VALORIZAÇÃO E PROMOÇÃO DO PATRIMÔNIO GEOLÓGICO PARANAENSE}

A história do Planeta Terra deixou capítulos interessantes e variados no que hoje é o estado do Paraná e este é um acervo sobre as memórias do território paranaense difundido ainda de modo precário e certamente insuficiente. Carneiro et al. (2004) expõem com propriedade os motivos de se incluir temas geológicos na educação básica, necessários para a formação de cidadãos responsáveis e consequentes. Os autores destacam os desafios de se levar o mundo real para a sala de aula e vice-versa, a atenção para a geoconservação das áreas especiais para a compreensão do passado geológico, preferencialmente tomando-se o cuidado de realizar a oferta cultural do patrimônio geológico local. Exemplos concretos e com resultados estimulantes, no Paraná e em estados vizinhos (Carneiro, 2007; Bruczkovski e Guimarães, 2011; Alencar et al., 2012), demonstram o potencial didático de elementos da geodiversidade na fixação de conteúdos de Ciências e Geografia do ensino fundamental e médio, tomando-se por base exemplos locais.

Outra maneira de aproximar o patrimônio geológico da comunidade em geral é através de museus e exposições. O Centro de Informações Minerais Professor Riad Salamuni e a Exposição de Minerais e Rochas Orville Derby, ambos situados na Mineropar, receberam visitas da ordem de 12.000 estudantes no ano de 2012 (PARANÁ, 2012). A externalização do acervo do laboratório didático de Geologia da Universidade Estadual de Ponta Grossa em corredores, saguões e área exterior de um de seus blocos didáticos, além da reprodução de quase todo o conjunto de painéis geológicos da Mineropar, trouxe a oportunidade de tanto a comunidade universitária como a de visitantes ocasionais tomarem conhecimento de elementos da geodiversidade em geral, e do patrimônio geológico paranaense em particular (Liccardo et al., 2012).

Museus, centros de divulgação e exposições acabam sendo, muitas vezes, a melhor forma de levar à população dois componentes da geodiversidade que, por questões de escala, fragilidade e/ou valor científico, normalmente não podem ser vistos em seus locais originais de coleta: fósseis e minerais. O estado do Paraná é uma referência nacional quando o assunto são os fósseis de invertebrados marinhos do Devoniano, a Fauna Malvinocáfrica. Apesar de serem conhecidos diversos afloramentos fossilíferos da Formação Ponta Grossa (Sequência Paraná), principalmente nos municípios de Ponta Grossa, Tibagi e Jaguariaíva (inclusive integrando a SIGEP; Bolzon et al., 2002), não há muito sentido em indicá-los para uma lista dos geossítios que divulguem à população em geral o patrimônio geológico paranaense, seja pela dificuldade de pronta observação dos fósseis, da necessidade de conservação de material de interesse científico ou restrições de acesso, conservação e segurança de alguns destes locais (como é o caso do Sítio SIGEP 65, em Jaguariaíva).

O "conjunto básico" de geossítios (A a G na Tabela 1) para contato com o patrimônio geológico do Paraná encontra-se, como já destacado, em unidades de conservação. Estas, em maior ou menor proporção, contam com mecanismos de proteção e divulgação (infelizmente excessivamente dirigidos à biodiversidade), algumas delas com equipamentos e pessoal voltados à exploração turística. Deve-se ressaltar que na lei federal que criou o Sistema Nacional de Unidades de Conservação da Natureza (SNUC; Brasil, 2000), onde são listados seus objetivos, estão explícitas as missões tanto de proteger como de permitir o acesso da população a elementos ímpares da natureza brasileira, os quais claramente incluem o patrimônio geológico:

(...)

VI - proteger paisagens naturais e pouco alteradas de notável beleza cênica;

VII - proteger as características relevantes de natureza geológica, geomorfológica, espeleológica, arqueológica, paleontológica e cultural;

VIII- proteger e recuperar recursos hidricos e edáficos;

(...)

$X$ - proporcionar meios e incentivos para atividades de pesquisa cientifica, estudos e monitoramento ambiental;

(...)

XII - favorecer condições e promover a educação e interpretação ambiental, a recreação em contato com a natureza e o turismo ecológico (artigo 4 da Lei Federal $9.985,2000)$.

Alguns dos principais destinos turísticos do Paraná possuem sua atratividade estreitamente vinculada à geodiversidade (Cataratas do Iguaçu, Ilha do Mel, Parque Estadual de Vila Velha), apesar dos operadores turísticos e gestores das unidades de conservação subestimarem o componente abiótico destes locais. Esforços têm ocorrido para superar esta deficiência, com a implantação de painéis explicativos, treinamentos de guias e condutores, elaboração de roteiros geoturísticos e participação nos conselhos consultivos das unidades de conservação (Melo, 2006; Guimarães et al., 2006; Letenski et al. 2009; Moreira, 2008, 2011), mas ainda há espaço para muito progresso (Melo et al., 2004; Guimarães et al., 2008).

Recentemente tem havido intensos debates sobre uma definição para geoturismo (Hose, 2011; Martini et al., 2012). Mas um consenso entre os teóricos desta vertente turística está no acréscimo de conhecimento a quem dele usufrui, o que implica a promoção de um ganho cultural. Portanto o geoturismo representa ao mesmo tempo uma ferramenta de conservação do patrimônio geológico, geração de renda e valorização e divulgação científico-cultural.

Instrumentos que podem auxiliar a 
disseminação do conhecimento sobre o patrimônio geológico, tanto no campo do geoturismo como da educação (formal, informal e não-formal), são os roteiros e guias geológicos. Há décadas a comunidade de geocientistas tem lançado mão do recurso da elaboração de roteiros para divulgar as peculiaridades da geodiversidade nacional, com ótimos exemplos no estado do Paraná (de Mendes, 1968 a Matsumura, 2010), inclusive culminando na realização do 10 Simpósio de Roteiros Geológicos do Paraná em 2002 (Fernandes et al., 2002).

Estes roteiros, frequentemente voltados a um público especializado (mineralizações de F, Pb e Ag: Lima e Silva, 1987; geologia e paleontologia da Bacia do Paraná: Zalán et al., 1987, Rösler et al., 2000; icnopaleontologia do Grupo Paraná: Tognoli et al., 2002; geologia do petróleo na Bacia do Paraná: Milani et al., 2006), também acabam por auxiliar novas gerações de professores universitários que buscam alternativas para seus trabalhos de campo. Apenas recentemente tem se percebido a publicação de roteiros que buscam atender profissionais das geociências que não diretamente geólogos, ou mesmo que pretendam mediar a transmissão de conhecimentos específicos para condutores de turismo e o público em geral (Letenski et al., 2009; Augusto \& Lama, 2010).

Seja porque possuam alcance restrito, muitas vezes acompanhando boletins de resumos ou atas de eventos científicos, ou pela linguagem excessivamente técnica, os roteiros atendem apenas parcialmente 0 papel de divulgação do patrimônio geológico. Folhetos, mapas e guias geoturísticos dirigidos ao público em geral, de uso consagrado no exterior, têm começado a ocupar este espaço no Paraná, complementando as funções exercidas por painéis, museus e condutores. A coleção de folhetos explicativos produzidos pela Mineropar (disponíveis em www.mineropar.pr.gov.br), os guias geoturísticos de Curitiba (Liccardo et al., 2008) e do carste na região metropolitana de Curitiba (Piekarz, 2011), o mapa geoturístico de Tibagi (Liccardo et al., 2010) e o mapa/folheto do patrimônio espeleológico de Ponta Grossa (GUPE, 2013) são exemplos que deveriam ser estendidos às demais áreas ilustrativas do patrimônio geológico do Paraná.

\section{CONSIDERAÇÕES FINAIS}

Nos últimos anos a sociedade brasileira tem visto, nos grandes veículos de divulgação em massa, um número cada vez maior de notícias relacionadas ao mundo profissional dos geólogos. As "descobertas do pré-sal", desastres naturais no Brasil (por exemplo, movimentos de massa em Santa Catarina, Rio de Janeiro e na região litorânea do Paraná) e no exterior (terremotos, tsunamis, erupções vulcânicas), novidades científicas no campo paleontológico ou astronômico (por exemplo, explicações sobre as missões norte-americanas em Marte) têm trazido geólogos aos programas de televisão, revistas, jornais, etc.

Também com frequência aparecem notícias destacando a necessidade do país em formar um número maior de geólogos. Isto tem levado a Geologia a ser apontada como uma das melhores opções profissionais, em publicações voltadas para estudantes do ensino básico, com garantias de inserção imediata no mercado de trabalho.

Por outro lado a constatação cotidiana indica que a sociedade em geral, como regra, possui uma enorme lacuna na compreensão de elementos básicos das geociências. Isto se revela no contato com alunos de disciplinas de Geologia Geral (e equivalentes) das séries iniciais do ensino superior (cursos de Engenharia, Agronomia, Geografia, Biologia). Também esta situação ocorre com profissionais de diferentes órgãos da administração pública, inclusive aqueles responsáveis pela prevenção de situações de risco a desastres naturais ou das políticas de uso e ocupação do solo.

No estado do Paraná há atualmente apenas um curso de graduação em Geologia, mas diversos cursos com disciplinas básicas das geociências em cursos de Geografia, Ciências Biológicas, Agronomia, Engenharia Civil, Química, dentre outros. No primeiro caso seria recomendável a oferta de disciplinas, aos futuros geólogos, que contemplassem estratégias de identificação, proteção e divulgação do patrimônio geológico, tais como Geoconservação e Geoturismo.

No que diz respeito à graduação de profissionais de outras áreas existe uma dupla missão. "Alfabetizar" geologicamente futuros bacharéis (biólogos, geógrafos, turismólogos, engenheiros etc.) e preparar para a tarefa de transmissão de conhecimento geocientífico aqueles que atuarão como professores do ensino fundamental e médio (principalmente professores de Geografia e Ciências).

Auxiliar a sociedade a perceber-se como elemento indissociável e integrante do mundo geológico é uma ação cultural que não deveria se resumir às universidades e bancos escolares, necessitando ser abraçada por indivíduos, associações e órgãos que congreguem profissionais das geociências. Em todas estas situações acredita-se que os exemplos do patrimônio geológico paranaense facilitarão o entendimento de aspectos básicos das geociências e suas implicações para a população em geral.

Agradecimentos: Os resultados e discussões aqui apresentados são oriundos, em parte, de projetos financiados pela Fundação Araucária e pela Mineropar, aos quais estendemos nossos agradecimentos. Os créditos das imagens deste artigo, quando não discriminados, pertencem aos autores. 


\section{Referências bibliográficas}

ALENCAR R., NASCIMENTO R. S., GUIMARÃES G. B. 2012. Geociências no Ensino Fundamental: Ciências ou Geografia? Da história da Terra à paisagem local através da geodiversidade da Ilha de Santa Catarina. In: III Simpósio Nacional de Ensino de Ciência e Tecnologia, Ponta Grossa/PR. Anais. UTFPr, Ponta Grossa, 12 p.

ANDRADA M. F. R. 1847. Diário de uma viagem mineralógica pela Província de S. Paulo no Anno de 1805. Revista do IHGSP, IX: 527-548.

AUGUSTO W. C. B., LAMA E. A. D. 2010. Roteiro geoturístico no centro da cidade de São Paulo. Terrae Didactica, 7(1): 18-29.

BOLZON R. T., AZEVEDO I., ASSINE M. L. 2002. Sítio Jaguariaíva, PR - invertebrados devonianos de grande importância paleobiogeográfica. In: SCHOBBENHAUS C., CAMPOS D.A., QUEIROZ E.T., WINGE M., BERBERT-BORN M. L. C. (eds) Sítios Geológicos e Paleontológicos do Brasil. DNPM/CPRM - Comissão Brasileira de Sítios Geológicos e Paleobiológicos (SIGEP), Brasília, 33-37 p.

BRASIL. 2000. Lei 9985 de 18 de julho de 2000. Institui o Sistema Nacional de Unidades de Conservação da Natureza-SNUC.

BRILHA J. B. R. 2005. Património geológico e geoconservação: a conservação da natureza na sua vertente geológica. Palimage, Braga, 190p.

BRUCZKOVSKI M., GUIMARÃES G. B. 2011. Geoconservação no Parque Estadual de Vila Velha (PR) como projeto pedagógico no ensino funadamental. In: 1ㅇ Simpósio Brasileiro de Patrimônio Geológico/ll Congresso LatinoAmericano e do Caribe sobre Iniciativas em Geoturismo, Rio de Janeiro/RJ. Atas. SBG RJ-ES, Rio de Janeiro, p. 50.

CARCAVILLA L., LÓPEZ-MARTÍNEZ J., DURÁN, J. J. 2007. Patrimonio geológico y geodiversidad: investigación, conservación, gestión y relación con los espacios naturales protegidos. Instituto Geológico y Minero de España. Serie Cuadernos del Museo Geominero, no 7, Madrid, 360p.

CARNEIRO C. D. R. 2007. Viagem virtual ao Aqüífero Botucatu (SP): formações Pirambóia e Botucatu, Bacia do Paraná. Terrae Didactica, 3(1): 50-73.

CARNEIRO C. D. R., TOLEDO M. C. M., ALMEIDA F. F. M. 2004. Dez motivos para a inclusão de temas de Geologia na educação básica. Revista Brasileira de Geociências, 34(4): 553-560.

FERNANDES L A, MELO M. S. FREITAS R. C. (orgs) 2002. 1응 Simpósio de Roteiros Geológicos do Paraná, Guia. SBG/PR, Curitiba, 96p.

GRAY M. 2004. Geodiversity: valuing and conserving abiotic nature. Wiley, Chichester, 434p.
GUIMARÃES G. B., MELO M. S., PIEKARZ G. F., LICCARDO A., FERNANDES L. A., MOREIRA J. C. 2006. Patrimônio natural dos Campos Gerais do Paraná: os monumentos geológicos e seu papel no geoturismo regional e na educação em geociências. In: 58a Reunião Anual da SBPC, Florianópolis/SC. Anais. D i s p o n íve I e $\mathrm{m}$ www.sbpcnet.org.br/livro/58ra/SENIOR/RESUMOS/ resumo_2050.html. Acesso em 11 de junho de 2013.

GUIMARÃES G. B., MELO M. S., PIEKARZ G. F., MOREIRA J. C. 2008. Desafios e conquistas da geoconservação no Parque Estadual de Vila Velha - Paraná. In: 44으 Congresso Brasileiro de Geologia, Curitiba/PR. Anais... SBG, Curitiba, p. 389.

GUIMARÃES G. B., MELO, M. S., MOCHIUTTI N. F. 2009. Desafios da geoconservação nos Campos Gerais do Paraná. Geologia USP - Série Publicação Especial, 5: 47-61.

GUPE - Grupo Universitário de Pesquisas Espeleológicas. 2013. Mapa de localização das cavidades areníticas de Ponta Grossa (PR). GUPE, Ponta Grossa.

HOSE T. A. 2011. The English origins of geotourism (as a vehicle for geoconservation) and their relevance to current studies. Acta Geographica Slovenica, 51(2): 343-360.

LETENSKI R., GUIMARÃES G. B., PIEKARZ G. F., MELO, M. S. 2009. Geoturismo no Parque Estadual de Vila Velha: nas trilhas da dissolução. Pesquisas em Turismo e Paisagens Cársticas, 2: 5-15.

LICCARDO A., CAVA L. T. 2006. Minas do Paraná. Imprensa Oficial, Curitiba, 165p.

LICCARDO A., PIEKARZ G. F., SALAMUNI E. 2008. Geoturismo em Curitiba. Mineropar, Curitiba, 122p.

LICCARDO A., HORNES K. L., GUIMARÃES G. B., PIEKARZ G. F. 2010. Mapa Geoturístico de Tibagi. Mineropar/UEPG/Prefeitura de Tibagi, Tibagi.

LICCARDO A., PRANDEL J. A., HUNDSDORFER M. A. R., GUIMARÃES G. B. 2012. Geodiversidade na educação - externalização do conteúdo do Laboratório de Geologia da UEPG e exposição didática. In: III Simpósio Nacional de Ensino de Ciência e Tecnologia, Ponta Grossa/PR. Anais. UTFPr, Ponta Grossa, 10 p.

LIMA F. F. 2008. Proposta metodológica para a inventariação do patrimônio geológico brasileiro. Dissertação de mestrado. Pós-graduação em Patrimônio Geológico e Geoconservação, Escola de Ciências, Universidade do Minho, Braga/Portugal, 91 f. Dis pon íve I e m http://www.dct.uminho.pt/mest/pgg/docs/tese_li ma.pdf. Acesso em 11 de junho de 2013. 
LIMA R. E., SILVA A. C. G. A. 1987. Roteiro de excursão Jazidas e minas de fluorita e chumbo-prata do Paraná. In: III Simpósio Sul-Brasileiro de Geologia, Curitiba/PR. Anais. SBG PR/SBG RS-SC, Curitiba, 72$79 \mathrm{p}$.

MARTINI G., ALCALÁ L., BRILHA J. B. R., IANTRIA L., SÁ A., TOURTELLOT J. 2012. Reflections about the geotourism concept. In: 11th European Geoparks Conference, Arouca/Portugal. Proceedings. Associação Geoparque Arouca, Arouca, 187-188 p.

MATSUMURA W. M. K. 2010. Roteiro geológico nos municípios de Castro e Tibagi, PR - Brasil. Dissertação de mestrado. Pós-graduação em Gestão do Território, Universidade Estadual de Ponta Grossa, Ponta Grossa, $191 \mathrm{f}$.

MELO M. S. 2006. Formas rochosas do Parque Estadual de Vila Velha. Editora da UEPG, Ponta Grossa, 145p.

MELO M. S., GODOY L. C., MENEGUZZO P. M., SILVA D. J. P. 2004. Geologia no plano de manejo do Parque Estadual de Vila Velha, PR. Revista Brasileira de Geociências, 34(4): 561-570.

MELO M. S., MORO R. S., GUIMARÃES G. B. 2007. Os Campos Gerais do Paraná. In: MELO M. S., MORO R. S., GUIMARÃES G. B. (eds) Patrimônio Natural dos Campos Gerais do Paraná. Editora UEPG, Ponta Grossa, 17-21 p.

MELO M. S., GUIMARÃES G. B. 2012. Campos Gerais do Paraná. In: HASUI Y., CARNEIRO C. D. R., ALMEIDA F. F. M., BARTORELLI A. (eds) Geologia do Brasil. Beca, São Paulo, 407-412 p.

MENDES J. C. 1968. Conheça o solo brasileiro. Polígono, São Paulo, 202p.

MILANI E. J., FRANÇA A. B., MEDEIROS R. A. 2006. Roteiros geológicos - Rochas geradoras e rochasreservatório da Bacia do Paraná, faixa oriental de afloramentos, Estado do Paraná. Boletim de Geociências da Petrobras, 15(1): 135-162.

MOCHIUTTI N. F. 2013. O patrimônio geológico no desenvolvimento territorial em Tibagi, Paraná. Dissertação de mestrado. Pós-graduação em Geografia, Universidade Federal de Santa Catarina, Florianópolis, $237 \mathrm{p}$.

MOREIRA J. C. 2008. Patrimônio geológico em unidades de conservação: atividades interpretativas, educativas e geoturísticas. Tese de doutorado. Pósgraduação em Geografia, Universidade Federal de Santa Catarina, Florianópolis, $428 \mathrm{f}$.

MOREIRA J. C. 2011. Geoturismo e interpretação ambiental. Editora UEPG, Ponta Grossa, 157p.

NASCIMENTO M. A. L., RUCHKYS U. A., MANTESSO-NETO V. 2008. Geodiversidade, Geoconservação e Geoturismo: trinômio importante para a proteção do patrimônio geológico. SBG, São Paulo, 81p.
PARANÁ 2012. Flávio Arns visita o centro de informações da Mineropar. Agência de notícias do Paraná, 07 nov. $2012 . \quad$ D i s p o n íve I e m http://www.aen.pr.gov.br/modules/noticias/article. php?storyid=71594\&tit=Flavio-Arns-visita-o-centrode-informacoes-da-Mineropar. Acesso em 11 de junho de 2013.

PIEKARZ G. F. 2011. Geoturismo no Karst. Mineropar, Curitiba, 121p.

PIEKARZ G. F., SALAMUNI E., CRÓSTA A. P., LICCARDO A., GUIMARÃES G. B. 2012. Tombamento e geoconservação - experiência paranaense. In: 46음 Congresso Brasileiro de Geologia, Santos/SP. Anais... SBG, Santos, CD-ROM.

PONCIANO L. C. M. O., CASTRO A. R. S. F., MACHADO D. M. C., FONSECA V. M. M., KUNZLER J. 2011. Patrimônio geológico-paleontológico in situ e ex situ: definições, vantagens, desvantagens e estratégias de conservação. In: CARVALHO I. S., SRIVASTAVA N. K., STROHSCHOEN Jr. O., LANA C. C. (eds) Paleontologia: cenários da vida. Interciência, Rio de Janeiro, v. 4, 853-869p.

RÖSLER O., ROHN R., SOUSA S. H. M. E., WEINSCHUTZ L. C. 2000. Field trip guide - Paraná Basin records of Siluro-Devonian to Permian-Triassic biological and environmental changes, Southern Brazil. In: 31st International Geological Congress, Rio de Janeiro/RJ. IUGS, Rio de Janeiro, $30 \mathrm{p}$.

SHARPLES C. 2002. Concepts and principles of geoconservation. Tasmanian Parks and Wildlife S e $r$ vice. Dis ponível e m http://www.dpiw.tas.gov.au/inter.nsf/Attachments/ SJON-57W3YM/\$FILE/geoconservation.pdf. Acesso em 11 de junho de 2013.

TOGNOLI F. M. W., ASSINE M. L., NETTO R. G. 2002. Roteiro icnológico do Grupo Paraná. IGCE/UNESP, Rio Claro, 27p.

WHITE I. C. 2008. Comissão de estudos das minas de carvão de pedra do Brazil - Relatório final do Dr. I. C. White chefe da comissão: 1 de julho de 1904 a 31 de maio de 1906. CPRM, Belo Horizonte, 617p.

ZALÁN P. V., CONCEIÇÃO J. C. J., ZANOTTO O. A., VOLFF Z. 1987. Roteiro de excursão - Estratigrafia e estruturas da Bacia do Paraná. In: III Simpósio Sul-Brasileiro de Geologia, Curitiba/PR. Anais. SBG PR/SBG RS-SC, Curitiba, 80-86 p. 